\title{
The Compendiosa of Thomas Geminus, Part 2
}

The first part of this article gave a brief account of what is known of Thomas Geminus. We shall now turn to some details of the Sibbald Library's copy of the first edition of I 545 before discussing the book's anatomical images.

Our copy of the first edition of the Compendiosa, ' which is overall in excellent condition, has the early state of two of the plates, as was mentioned in Part I of this article. ${ }^{2}$ It presents two other points of considerable interest in its provenance. The most obvious is the signature of the Jacobean theatrical producer, artist and architect Inigo Jones at the bottom right of the title page (Figure IA). Less obvious, at the bottom centre of the image, we find written in a contemporary hand 'Desneux Chirurg.' (Figure IB). On the obverse of the title page, again in a contemporary hand, there is 'Franciscus Rasseus Noëus Chirurgus paris[iensis?]. 1546' (Figure IC).

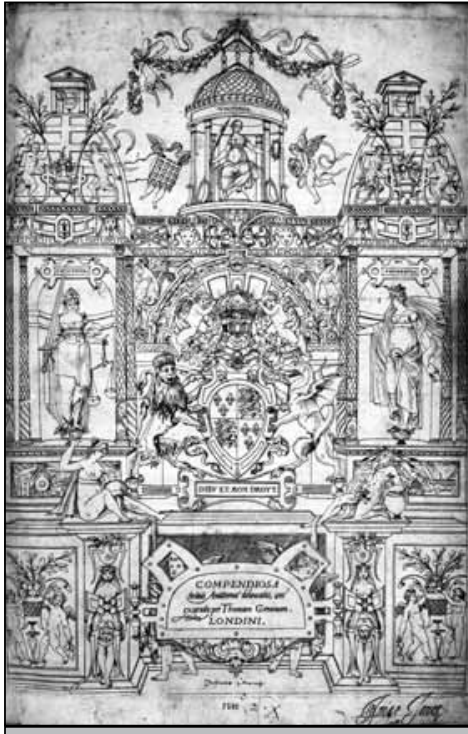

EX LIBRIS RCPE

Compendiosa totius anatomie delineatio, ere exarata: per

Thomam Geminum. London, 1545
The annotation on the title page is that typically used by the Parisian surgeon and avid book

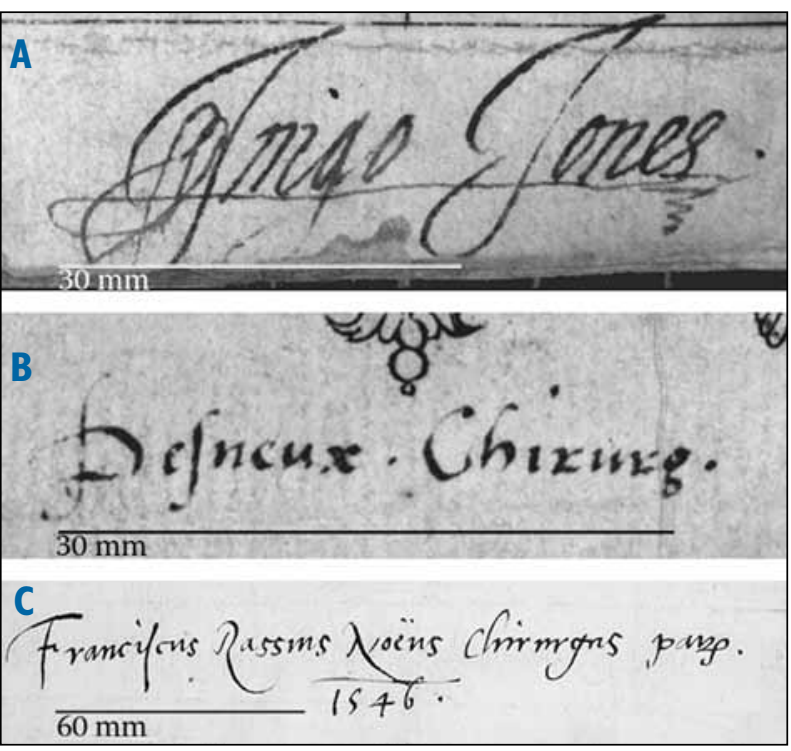

FIGURE I Annotations by owners on the title page of the copy of the 1545 Compendiosa in the Sibbald Library.

A: Signature of Inigo Jones (1573-1652).

B:Annotation Desneux Chirurg. the short Ex libris of

François Rasse Desneux, placed, as was his custom, near the centre bottom of the title page.

$\mathrm{C}:$ On the obverse of the title page, Franciscus Rasseus Noëus Chirurgus Paris[iensis?] 1546.

Note different scales of the three images. collector François Rasse Desneux (ca. |526-8I) and the text on the obverse confirms this and dates his ownership of the book to 1546, the year after its publication. Rasse was not only an avid book collector, he was an avid annotator of his books and diarist and these annotations, studied in detail by Jeanne Veyrin-Forrer, ${ }^{3}$ have provided some information about his life. It has been suggested that Rasse, son of a royal surgeon, began his surgical apprenticeship about 1544 (having previously been a student in arts) ${ }^{3}$ and his purchase of Geminus's Compendiosa in I 546 would fit well with this. He was awarded the maitrise - the highest qualification in surgery of the Collège de St Côme - in 1548.

That Rasse became a more than competent anatomist is shown by a record of a public dissection he carried out on 2 April 1555, which resulted in a laudatory note by the Dean of the Faculté de Médecine in the Faculty records. Thus the Compendiosa is likely to have been more than just another book collector's item for him. In I552 Rasse, together with Estienne de la Rivière, was associated with Ambroise Paré in his test of the possibility of arresting bleeding by ligaturing the cut vessels rather than with cautery following amputation of a limb $b^{4}$ - a test that was so successful that Paré adopted the ligature in amputation in place of cautery; the practice soon became widespread (though not universal) and represents a very significant surgical advance indeed.

It is likely that Rasse was also present at the examination of the already famous Paré for the baccalauréat, then the maîtrise of the Collège in 1554. In I56I Rasse was prévot (provost, sometimes called Dean) of the Collège de St Côme. Although he is remembered now - when he is remembered at all - as a book collector, Rasse was a distinguished surgeon, an amateur poet and a friend of poets such as the physician and editor, commentator and translator of Vesalius's Epitome, Jacques Grévin. Like both Paré - also an amateur poet - and Grévin, Rasse was a protestant.

Since Inigo Jones died in 1652 the copy must have been back in England (probably in London) before then. But for Jones, unlike Rasse, it is not immediately obvious why an anatomy book should have been of interest; perhaps he was simply interested in the images as an artist and designer. 
The relation of the text(s) to the plates

After the alterations made to two of the plates during the course of the first edition, ${ }^{2}$ the images remained stable and identical throughout the second and third editions (I553 and 1559). The text, however, presents a number of questions. In the first edition the text, in Latin, consists of Vesalius's legends to the plates which, with the exception of the Adam \& Eve plate (see inside front cover), derive from the large woodcuts of the Fabrica of 1543, together with some of the smaller woodcuts, which are separate in the Fabrica, the copies of which have been grouped together on a single plate. However, the Latin text, apart from the legends, is taken not from the Fabrica but from the Epitome, also published in 1543 as an abbreviated work principally for students. Although a few images are shared by the Fabrica and the Epitome, the texts of the two works are completely different and, not surprisingly, the text of the Epitome does not fit at all with the images from the Fabrica which it accompanies in the first edition of the Compendiosa.

The introduction to the first edition speaks of King Henry VIII having encouraged Geminus to make his images available widely and it may be that the text was added - perhaps hastily - as an afterthought. In spite of the unsatisfactory marriage of text and images the work seems to have been popular and Geminus claimed in the dedication (to Edward VI) of the second edition - which has an English text - that it had been successful 'and hath dooen muche good in Italy, Fraunce, Spayne, Germaine, and other foren parties'. The dedications also make it clear that an important purpose of the book was to aid the instruction of surgeons, leading Geminus to say 'that the same worke beeying set foorth in the English tounge might greatly availe to ye knowlage of the unlatined surgeons, \& by meane of them, should bee muche more beneficiall, then in latin it is to an infinite nombre of people in thys your Maiesties Royalme of Englande.'

But Geminus himself, he says, is not sufficiently fluent in English to produce such a text so he has engaged the help of others, principally Nicholas Udall. Udall, though an accomplished classicist and a playwright, was a strange choice since there is no evidence that he had any knowledge of anatomy. Nevertheless, one supposes that he could have translated Vesalius's Latin, had he been set this task. But this is not at all what happened.

The English text of the second and third editions has no connection with Vesalius and is fairly certainly derived ultimately from a mediæval text by the surgeon Henri de Mondeville via a now-lost English anatomical text by the Elizabethan surgeon Vicary. This text, also, does not fit the images and its choice for the Compendiosa remains puzzling. For details of the texts of the Compendiosa beyond this simplified account see Larkey ${ }^{5}$ and O'Malley. ${ }^{6}$

Significantly, when Geminus's images were reused though without any mention of Geminus - by André

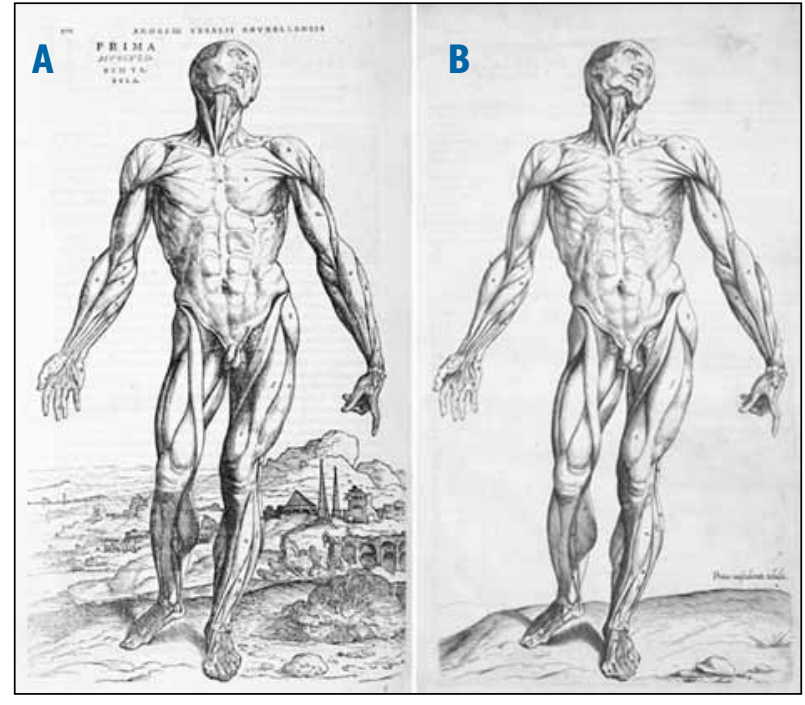

FIGURE 2 The first muscleman.

A: woodcut from Vesalius's Fabrica of 1543.

B: copper-plate engraving from Geminus's Compendiosa of 1545.

Note the suppression of most of the background by

Geminus. (From copies in the Sibbald Library.)

Wechel and Jacques Grévin in Paris in 1564 and 1569,2 they were accompanied by Vesalius's Latin text from the Epitome revised by Grévin in 1564, and by a French translation of this text by Grévin with an added commentary in 1569. Once again, it seems, the publisher had realised that there would be a ready market for a book in which the images were accompanied by a vernacular, rather than by a Latin, text.

\section{The plates}

Geminus's work has often been described as a plagiarism of Vesalius's woodcuts (for example, by O'Malley ${ }^{6}$ ), but this is less than fair since Geminus was quite open about his copying of the woodcuts and, far from attempting to present them as his own work, explained his admiration for Vesalius. In the 1545 dedication to Henry VIII Geminus says: "When I was to draw out the whole [body] with all the parts I followed Master Andreas Vesalius of Brussels by far the most skilled man of our times in that art...' That said, the copying was completely unauthorised and it is not surprising that Vesalius was displeased.

But Vesalius's damning of the work as poorly executed, incompetent and a travesty is not justified. The engravings are exact copies of the Vesalian woodcuts, except for the great simplification of the backgrounds of the figures of progressive dissection of the muscles, layer by layer (the 'Musclemen') which in no way affects the anatomy - see, for example, Figure 2. Geminus's engraving is more than competent.

Including the title page there are $4 \mathrm{I}$ pages of engravings printed from 50 copper plates. These are printed each on a separate sheet of paper, on one side of the paper 
only. The text is also printed on single sheets, but on both sides of the sheet. The books are thus technically broadsides rather than folios - although they are often wrongly catalogued as the latter.

All the images come from the Fabrica, with one exception, the so-called Adam \& Eve plate (see inside front cover), whose figures are derived from two woodcuts in the Epitome which do not appear in the Fabrica. This plate is also unique because Geminus has altered the male figure which in Vesalius's woodcut carries a skull, to carry an apple. The skull lying between the figures is derived from a figure in the Fabrica to which Geminus has added the snake. The iconography obviously refers to Adam and Eve, whereas Vesalius's male and female figures have no such definite reference and present the figures simply as illustrations of surface anatomy. Quite why Geminus chose to represent the figures as Adam and Eve is not clear, but there was apparently quite an industry in printing Adam and Eve figures both before and, particularly, after Geminus.

Some of these figures were presented as 'fugitive sheets' and, in some cases they were equipped with pasted-on flaps that could be raised to show the internal anatomy. The survival of these un-bound sheets was necessarily precarious but enough have survived to suggest that they were quite common. Vesalius designed some of the figures in the Epitome to be cut out and pasted on to others as flaps, but this does not apply to his male and female nudes which Geminus borrowed. The quite complicated history of fugitive sheets, including Adam \& Eve examples, was described in detail by Crummer. ${ }^{7}$
There is only space here to show a single example of the relation between Geminus's images and the parent Vesalian woodcuts; Figure 2 shows the first of the Musclemen, with the woodcut in the Fabrica on the left and Geminus's copy of the figure on the right. Apart from the obvious suppression of most of the complicated background of the woodcut, it is obvious, even at this small size, that the images of the dissected figure are very closely similar. Examination at higher magnifications confirms that the copy is exact down to the smallest detail. The legend of the woodcut is printed from type, whereas that on the engraving is engraved on the plate itself. Comparisons using the more sophisticated technique described in 2010 confirm the exactness of the copy. ${ }^{8}$ An example of the results of this technique can be seen on the website Ars Anatomica (http://www.arsanatomica.lib.ed.ac.uk).

Those interested in further information about the content of the Compendiosa may also like to consult the Ars Anatomica website, which is a collaborative project between the University of Edinburgh and the Sibbald Library of the RCPE. It presents high-resolution images of all the woodcuts of the Fabrica, all the Geminus engravings and other anatomical images influenced by those of Vesalius and Geminus, together with translations of figure legends and brief commentaries.

IML Donaldson, Honorary Librarian, RCPE

(email: i.m.l.d@ed.ac.uk)

\section{REFERENCES}

I Geminus T. Compendiosa totius anatomie delineatio, ære exarata: per Thomam Geminum. London: John Herford; 1545.

2 Donaldson IML.The Compendiosa of Thomas Geminus Part I.J R Coll Physicians Edinb 2014; 44:85-7. http://dx.doi.org//0.4997/ |RCPE.2014.II9

3 Veyrin-Forrer J. Un collectionneur engagé, François Rasse des Neux, chirurgien parisien, in La Lettre et le texte : trente années de recherches sur l'histoire du livre. Paris: École normale supérieure de jeunes filles; 1987. p.423-77.

4 Paré A. Les oeuvres de M. Ambroise Paré conseiller, et premier chirurgien du Roy avec les figures \& portraicts tant de l'Anatomie que des instruments de Chirurgie, \& de plusieurs Monstres. Paris: Gabriel Buon; I575 p.4II-2
5 Larkey SV. The Vesalian Compendium of Geminus and Nicholas Udall's translation. Transactions of the Bibliographical Society (2nd series) 1933; 13:367-94.

6 O'Malley CD. Thomas Geminus Compendiosa totius anatomie delineatio. A facsimile of the first English edition of 1553 in the version of Nicholas Udall; with an introduction by CD O'Malley. London: Dawson's of Pall Mall; 1959

7 Crummer L Early anatomical fugitive sheets. Ann Med Hist 1923; 5:186-209.

8 Donaldson IML. Two states of some plates in the Compendiosa of Thomas Geminus (1545). The Library (7th series) 2010; 1 1:89-104. 


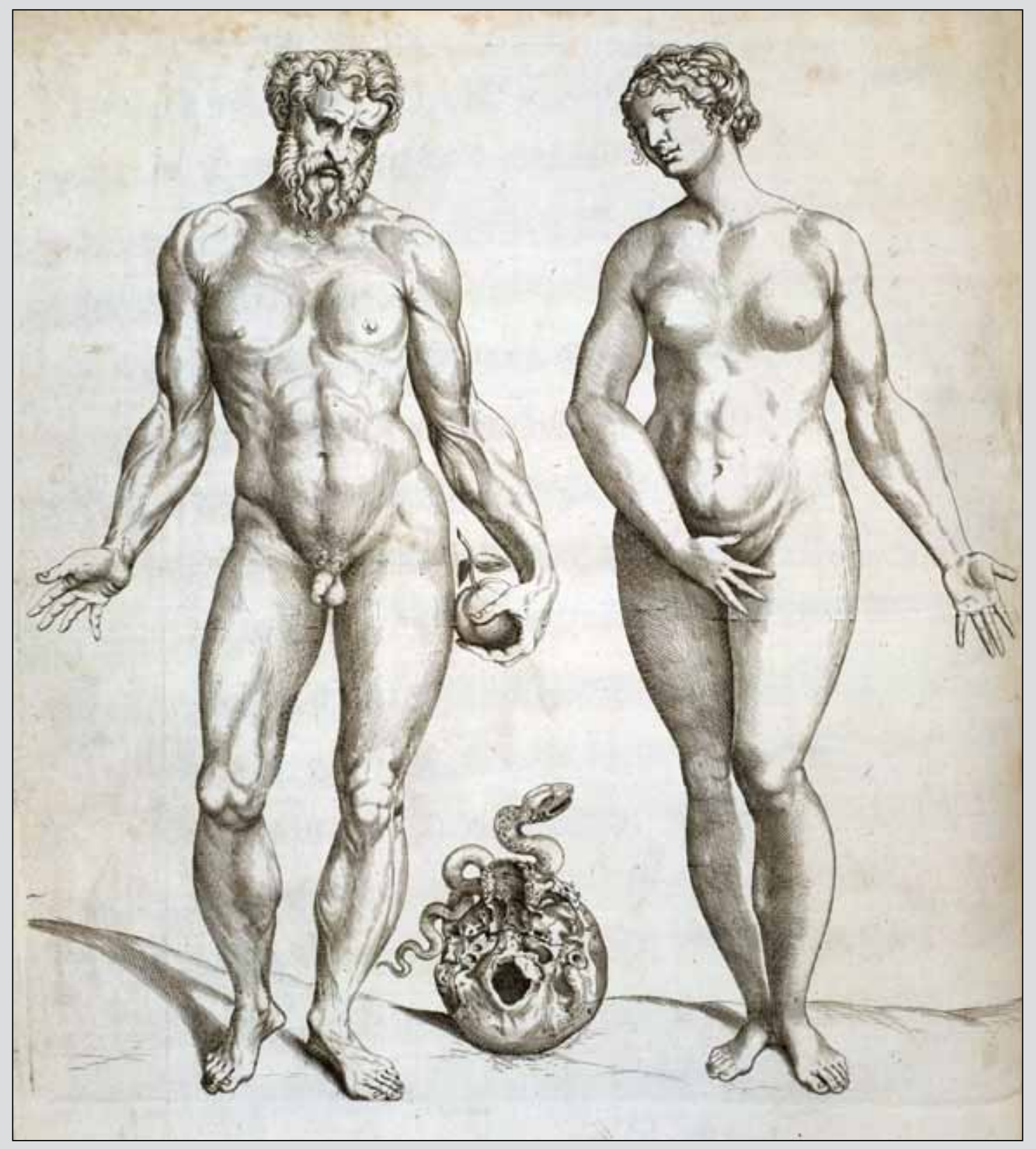

The 'Adam \& Eve' plate from the first edition of Compendiosa totius anatomie delineatio, ære exarata: per Thomam Geminum, London I545. This fold-out plate is derived from two separate woodcuts in the Epitome, a short summary of human anatomy by Andreas Vesalius published in the same year (1543) as his great Fabrica, principally for the use of students. It is the only image in the Compendiosa derived from the Epitome, all the others are from the Fabrica. The other images are exact copies of the Vesalian woodcuts, but in this plate Geminus has combined the two separate male and female figures and altered the male figure to carry an apple rather than the skull he holds in the Epitome. Geminus added the skull on the ground between the figures, taken from an image in the Fabrica, to which he then added a snake. The reference in this plate to Adam and Eve is unmistakable, whereas the original woodcuts carry no such reference and are presented just as models of surface anatomy. For more details see the article on pages 180-2 of this issue. 